\title{
Isomerisation Reactions of Dicyclopentadiene Derivatives. Preparation of Amides and Carboxylic Acids
}

\author{
Jan M. Bakke and Børre Knudsen
}

Organic Chemistry Laboratories, Norwegian Institute of Technology, University of Trondheim, N-7034 Trondheim, Norway

\begin{abstract}
Bakke, J. M. and Knudsen, B., 1994. Isomerisation Reactions of Dicyclopentadiene Derivatives. Preparation of Amides and Carboxylic Acids. - Acta Chem. Scand. 48: 234-239 (1) Acta Chemica Scandinavica 1994.

The dicyclopentadiene (DPD) derivatives 8,9-endo-dihydro-DPD (1), 8-exo-hydroxy-exo-tetrahydro-DPD (2) and 2-hydroxy-endo-tetrahydro-DPD (3) have been reacted with acetonitrile in sulfuric acid. Reaction for $6 \mathrm{~h}$ at $30^{\circ} \mathrm{C}$ gave an $82 \%$ yield of $\mathrm{N}$-(2-exo-tetrahydro-DPD-yl)acetamide (5a). Reaction of 3 for $1 \mathrm{~min}$ at $20^{\circ} \mathrm{C}$ gave $N$-(2-endo-tetrahydro-DPD-yl)acetamide $(\mathbf{4 a}, 95 \%$ yield) and reaction of 2 with acetonitrile and boron trifluoride in sulfur dioxide gave a $95 \%$ yield of $N$-(exo-8-exo-tetrahydro-DPD-yl)acetamide (6a). The reactions of 3 with benzonitrile and substituted benzonitriles were monitored by ${ }^{1} \mathrm{H}$ NMR spectroscopy. The observed rate constants could be correlated by the Hammett $\sigma$ " constants with a $\rho$ constant of $1.00\left(R^{2}=0.987\right)$. These results were in accordance with a reaction scheme in which the isomerisations proceed via carbocations in equilibria with nitrile adducts. Reaction of 8-exo-chloro-exo-tetrahydro-DPD (13) with carbon monoxide and antimony pentafluoride in sulfur dioxide gave 2-carboxy-endotetrahydro-DPD (15) at $-78^{\circ} \mathrm{C}$ and 2-carboxy-exo-2-tetrahydro-DPD (17) at $20^{\circ} \mathrm{C}$.
\end{abstract}

endo-Dicyclopentadiene (endo-DPD, endo-tricyclo$\left[5.2 \cdot 1.0^{2,6}\right]$ deca-3,8-diene) and its derivatives are readily available starting materials for organic syntheses. We have been interested in the reactions of these compounds and now report isomerisation reactions under acidic conditions of some derivatives. ${ }^{1-3}$ These reactions may give different results according to the conditions used. With superacids, adamantane and adamantane derivatives are produced, ${ }^{4-6}$ while the use of less strong acids gives derivatives of exo-tetrahydro-DPD (exo-THDPD) ${ }^{7,8}$ To obtain reactions of preparative value we have now reacted a series of readily available DPD derivatives with sulfuric acid and various nucleophiles.

\section{Results and discussion}

We have used 8,9-endo-dihydro-DPD (endo-DHDPD, 1), 8-exo-hydroxy-exo-THDPD (2), 2-hydroxy-endoTHDPD (3) and 8-exo-chloro-exo-THDPD (13) as starting materials for the reactions. They are all available from endo-DPD: 1 by partial hydrogenation of endo-DPD, 2 from acid-catalysed hydration of endo-DPD followed by hydrogenation, ${ }^{9} 3$ by $\mathrm{RuO}_{4}$ oxidation of endo-THDPD ${ }^{1}$ and 13 by addition of $\mathrm{HCl}$ to DPD followed by hydrogenation. ${ }^{9}$

Under acidic conditions, the first step in the reaction of these compounds is the formation of carbocations $\mathrm{s}^{4-6}$ which may undergo isomerisation or polymerisation re- actions, or react with nucleophiles present. In the absence of nucleophiles the reactions in sulfuric acid gave tars only. To avoid the polymerisation reactions and to obtain a high degree of isomerisation, we reacted the DPD derivatives with nucleophiles that could be reversibly bonded to the carbocations. By this it was anticipated that the carbocations would be able to undergo several consecutive isomerisation reactions leading to products that might be of interest.

We therefore tried several nitriles, carbon monoxide, methanol, diethyl ether, methyl iodide and propyl chloride as nucleophiles in the reactions of 1,2 and 3 in sulfuric acid. Of these, only the use of nitriles and carbon monoxide gave isolable products. With the others, either tars or very complex mixtures were produced.

Reactions with nitriles. In Table 1 are given the results from the reaction of endo-DHDPD (1), 8-exo-hydroxyexo-THDPD (2) and 2-hydroxy-endo-THDPD (3) with acetonitrile under acidic conditions. It is evident that the three $N$-substituted acetamides $4 \mathbf{4}, 5 \mathbf{5}$ and $6 \mathbf{6}$ are available in high yields from readily available starting materials by the right choice of reaction conditions. Thus, the acetamide 5a was produced in $83 \%$ yield from both endoDHDPD (1) and 8-exo-hydroxy-exo-THDPD (2) by reaction with acetonitrile in concentrated sulfuric acid after prolonged reaction time at room temperature. The formation of the amide 5a or other analogues amides has not been reported before. On the other hand, the amide $\mathbf{4 a}$ 
Table 1. Product composition from the reaction of endo-8,9-DHDPD (1), 8-exo-hydroxy-exo-THDPD (2) and 2-hydroxy-endoTHDPD (3) with acetonitrile and acids. For details, see the Experimental.

\begin{tabular}{|c|c|c|c|c|c|c|c|}
\hline \multirow[b]{2}{*}{ Substrate } & \multirow[b]{2}{*}{ Acid } & \multirow[b]{2}{*}{$T /{ }^{\circ} \mathrm{C}$} & \multirow{2}{*}{$\begin{array}{l}\text { Reaction } \\
\text { time/h }\end{array}$} & \multicolumn{4}{|c|}{ Yield (\%) } \\
\hline & & & & 3 & 4 & 5 & 6 \\
\hline 1 & $\mathrm{H}_{2} \mathrm{SO}_{4}$ & 15 & 1 & 41 & 6 & 15 & 30 \\
\hline 1 & $\mathrm{H}_{2} \mathrm{SO}_{4}$ & 20 & 24 & 2 & - & 83 & 6 \\
\hline 1 & $\mathrm{H}_{2} \mathrm{SO}_{4}$ & 30 & 6 & 2 & - & 82 & 7 \\
\hline 1 & $\mathrm{H}_{2} \mathrm{SO}_{4}$ & 50 & 6 & \multicolumn{4}{|c|}{ Complex reaction mixture } \\
\hline 1 & $\mathrm{CF}_{3} \mathrm{SO}_{3} \mathrm{H}-\mathrm{SO}_{2}$ & 20 & 24 & 2 & 2 & 68 & 6 \\
\hline 2 & $\mathrm{H}_{2} \mathrm{SO}_{4}$ & 20 & 1 & 5 & - & 62 & 23 \\
\hline 2 & $\mathrm{H}_{2} \mathrm{SO}_{4}$ & 20 & 24 & 2 & - & 84 & 8 \\
\hline 2 & $\mathrm{BF}_{3}-\mathrm{SO}_{2}$ & -20 & 24 & - & - & - & 95 \\
\hline 3 & $\mathrm{H}_{2} \mathrm{SO}_{4}$ & 20 & $1 / 60$ & 2 & 95 & - & - \\
\hline
\end{tabular}

was obtained in $95 \%$ yield if a one minute reaction time was used for the reaction of 2-hydroxy-endo-THDPD (3) with acetonitrile in sulfuric acid. This compound has been obtained earlier in $55 \%$ yield by a procedure similar to that reported here. ${ }^{10}$ The amide $6 \mathbf{a}$, obtained in $95 \%$ yield from 8-exo-hydroxy-exo-THDPD (2) by the use of boron trifluoride in liquid sulfur dioxide, has been made in a multistep synthesis from DPD starting with the addition of nitrosyl chloride, with a total yield of $56 \%{ }^{11}$ We obtained the same compound from a Ritter reaction of endoDPD with acetonitrile, followed by hydrogenation. The acid-catalysed addition of nucleophiles to endo-DPD gives the 8-substituted exo-DHDPD. ${ }^{7-9}$ The exo position of the acetamido substituent followed from the ${ }^{1} \mathrm{H}$ NMR spectrum: the signal from the proton at $\mathrm{C} 8$ (see compound 1 in Scheme 1 for numbering) was a triplet
$(J=7.5 \mathrm{~Hz})$ of doublets $(J=3.65 \mathrm{~Hz})$ showing this proton to be in an endo position (an exo position would have produced a triplet of triplets).

These reactions are examples of Ritter reactions. ${ }^{12}$ To widen the scope of the reaction and also to obtain information on its mechanism, we reacted 2-hydroxy-endoTHDPD (3) with benzonitrile and substituted benzonitriles in sulfuric acid. If one or more of the carbocations in the stepwise isomerisation ${ }^{4,5}$ were in equilibrium with the corresponding nitrile adduct (Scheme 1), the rate of reaction would be expected to depend on the nitrile used. If, on the other hand, the role of the nitrile was only to protect the final cations, the rate would be independent of the type of nitrile used.

In a preliminary experiment, the alcohol 3 was dissolved in a small volume of dichloromethane and added

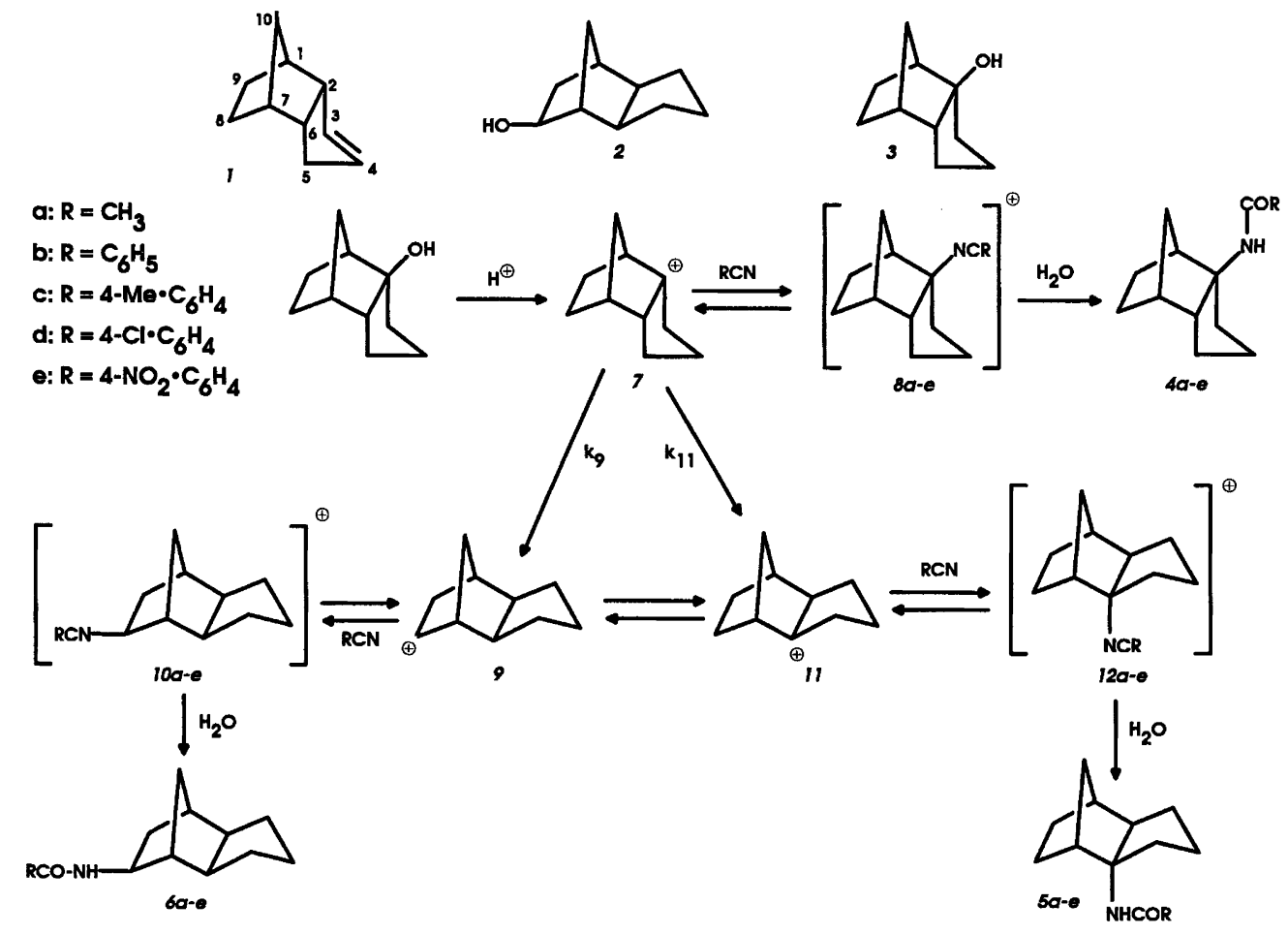

Scheme 1. 
to concentrated sulfuric acid. The mixture was then poured over ice. All the alcohol had reacted after $15 \mathrm{~s}$. By this procedure, only tars were produced, but the result indicates a rapid reaction of the alcohol 3 . When the reaction was run in presence of benzonitrile at $0^{\circ} \mathrm{C}$ and monitored by ${ }^{1} \mathrm{H}$ NMR spectroscopy, a spectrum was obtained which did not change with time and which was different from that of the starting material. Quenching the reaction with methanol gave a 1:1 mixture of 2-methoxyendo-THDPD and the benzamide $\mathbf{4 b}$. This showed that the reaction mixture before quenching consisted of the cation 7 (in equilibrium with its enantiomeric cation by 1,2-hydride shifts) and the nitrile adduct $\mathbf{8 b}$ and that no isomerisation took place at $0^{\circ} \mathrm{C}$. The composition of the product mixture did not reflect the ratio $\mathbf{7 : 8 b}$ as the composition was not reproducible in repeated experiments. However, with the high concentration of nitriles present, the equilibrium 7:8b must be well over on the nitrile adduct side.

The NMR spectrum of the equilibrium mixture 7:8b at $0{ }^{\circ} \mathrm{C}$ was complex but showed two signals at 3.10 and $2.95 \mathrm{ppm}$ from $\mathrm{Me}_{4} \mathrm{Si}$, each integrating for one proton. In the spectrum of the alcohol 3 itself, the signals from the protons at $\mathrm{Cl}$ and $\mathrm{C} 6$ were observed at 2.11 and $2.03 \mathrm{ppm}$ (from $\mathrm{Me}_{4} \mathrm{Si}$ ), respectively, the first as a doublet, the second as a quartet. ${ }^{13}$ The two signals at lowest field in the spectrum of the reaction mixture at $0^{\circ} \mathrm{C}(3.10$ and $2.95 \mathrm{ppm}$ ) were assigned to the protons at $\mathrm{C} 1$ and $\mathrm{C} 6$ of 7:8b as they were vicinal to $\mathrm{C} 2$ with a partial positive charge.

On increasing the reaction temperature from $0^{\circ} \mathrm{C}$ (at which temperature the ${ }^{1} \mathrm{H}$ NMR spectrum did not change with time) to $30^{\circ} \mathrm{C}$, the two signals at 3.10 and $2.95 \mathrm{ppm}$ gradually disappeared and three new ones appeared at $4.45,2.85$ and $2.75 \mathrm{ppm}$. Quenching the reaction mixture with water produced three benzamides, $\mathbf{4 b}, \mathbf{5 b}$ and $\mathbf{6 b}$. The reaction mixture thus consisted of the three ion pairs 7:8b, 9:10b and 11:12b before quenching. From this we assigned the signal at $4.45 \mathrm{ppm}$ to the proton at $\mathrm{C} 8$ of the ion pair 9:10b as this would be more deshielded than the protons of the pairs $7: 8 \mathrm{~b}$ and $11: 12 \mathrm{~b}$. The signal at $4.45 \mathrm{ppm}$ had a 1:1 ratio to the one at $2.75 \mathrm{ppm}$ throughout the experiment and we therefore assumed these two to originate from the same species. The signal at $2.85 \mathrm{ppm}$ was then assigned to the pair 11:12b.

These assignments were used to monitor the reactions of the alcohol 3 with benzonitrile and 4-methyl-, 4-chloroand 4-nitro-benzonitrile in concentrated sulfuric acid. The reactions were run under pseudo-first-order conditions with a 1:10 ratio of 3:nitrile. The disappearance of the signal at $3.10 \mathrm{ppm}$ showed first-order behaviour and the first-order rate constants are given as $k_{\mathrm{obs}}$ in Table 2 together with the relevant Hammett $\sigma$ constants. The results from a typical experiment are presented in Fig. 1.

We assumed the rearrangements to have taken place via carbocations (Scheme 1). The reactions from 7 to 9 and 11 would go via several ionic intermediates, ${ }^{14,15}$ each of which might be in equilibrium with the corresponding
Table 2. First-order rate constants for the disappearance of a signal at ca. $3.1 \mathrm{ppm}^{a}$ on the reaction of 2-hydroxy-endoTHDPD $(3,0.505 \mathrm{mmol})$ in sulfuric acid $(5 \mathrm{ml})$ with benzonitriles $(4.97 \mathrm{mmol})$ at $30^{\circ} \mathrm{C}$.

\begin{tabular}{lrll}
\hline $\mathrm{NCC}_{6} \mathrm{H}_{4} \mathrm{X}-4$ & $\sigma^{-}$ & $k_{\text {obs }} / \mathrm{min}^{-1}$ & $R^{2 b}$ \\
\hline Hydrogen & \multicolumn{1}{c}{0} & $0.018(1)$ & 0.98 \\
Methyl & -0.17 & $0.015(2)$ & 0.96 \\
Chloro & 0.23 & $0.025(1)$ & 0.99 \\
Nitro & 1.27 & $0.37(7)$ & 0.96 \\
\hline
\end{tabular}

${ }^{a}$ For the reaction with 4-nitrobenzonitrile, the signal at $3.20 \mathrm{ppm}$ was used. ${ }^{b}$ Correlation coefficient for the determination of $k_{\text {obs }}$.

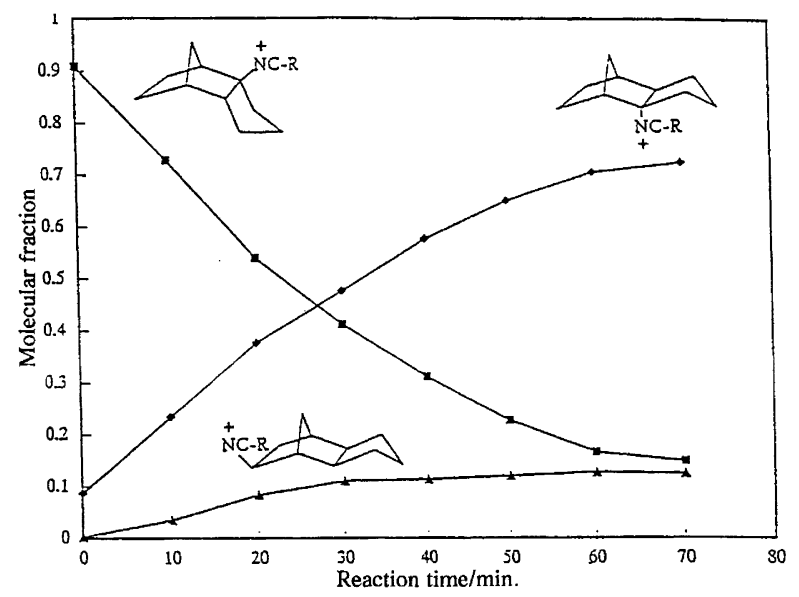

Fig. 1. Variation with time in the composition of the reaction mixture from 3-p-chlorobenzonitrile- $\mathrm{H}_{2} \mathrm{SO}_{4}$ at $30^{\circ} \mathrm{C}$.

nitrile adducts. The rate constants in Scheme 1, $k_{9}$ and $k_{11}$, are thus composed of several rate and equilibrium constants. The three carbocations in Scheme 1 have been studied in a non-nucleophilic environment. The order of stability was found to be $7>\mathbf{1 1} \gg \mathbf{9}$. However, the stability of the hydrocarbons was in the order exoTHDPD>endo-THDPD. ${ }^{14}$ The results in Fig. 1 indicate that this also was the case for the nitrile adducts $\mathbf{8 , 1 0}$ and 12 as there was a transformation of the endo-adduct $\mathbf{8}$ to the exo-adducts $\mathbf{1 0}$ and $\mathbf{1 2}$. When the reactions were run for $24 \mathrm{~h}$ and then quenched, the amides corresponding to the ions $\mathbf{1 0}$ and $\mathbf{1 2}$ were obtained with only traces of that corresponding to $\mathbf{8}$. If there was an equilibrium between the endo and exo series of THDPD it was far over to the exo side and the reactions of 7 to 9 and $\mathbf{1 1}$ were therefore, in essence, irreversible. This was also reflected in the first-order kinetics observed over several half-lives. In a non-nucleophilic environment $\left(\mathrm{SbF}_{5}-\right.$ $\mathrm{SO}_{2}$ ) the cation 9 rapidly isomerised to 7 even at $-78^{\circ} \mathrm{C} .{ }^{15}$ The carbocation 9 in the reactions reported here in the presence of nitriles was presumably formed by the reverse reactions.

The ratio $(9: 10):(11: 12)$ was constant throughout the experiments. This indicated that either the ion pairs 9:10 and 11:12 were in rapid equilibrium, e.g., by 1,3-hydride shifts of the carbocations, or that these ions were formed 
in competing reactions from 7 . In separate experiments 8-exo-hydroxy-exo-THDPD (2) was reacted with benzonitriles in concentrated sulfuric acid (Table 3). This compound would give the cation 9 on reaction with sulfuric acid. From the yields of the amides 5 and $\mathbf{6}$, the equilibration of the carbocations 9 and $\mathbf{1 1}$ was not complete after $1 \mathrm{~h}$ at $10^{\circ} \mathrm{C}$ with benzonitrile and 4-chlorobenzonitrile present but in the case of 4-nitrobenzonitrile appeared to be so. The equilibration of 9 with 11 was therefore not instantaneous and also depended on the nitrile used. The ions $\mathbf{9}$ and $\mathbf{1 1}$ may therefore have been formed either directly from 7 or in an equilibration reaction. The importance of the two routes would depend on the nitrile used in the reaction.

From Scheme 1, the rate of reaction would be given by eqn. (1). As the rate of the reaction depended on the

$$
-\mathrm{d}[7] / \mathrm{d} t=\left(k_{9}+k_{11}\right)[7]
$$

nitriles used (Table 2), their role in the reactions was not only to trap the final product ions. Instead, this indicated that the nitriles also participated in the reaction, e.g., as in Scheme 1. Nitriles are very weakly basic compounds and even in $98 \%$ sulfuric acid they are only partly protonated. ${ }^{16-18}$ We therefore assumed that it was the free and not the protonated nitriles that reacted. From Scheme 1 and eqn. (1) the rate of the isomerisation reactions would increase with the concentration of the free carbocation 7 . The equilibrium $K_{1}=[8] /[7]$ and thereby [7] must depend on the nucleophilicity of the nitriles and this again on the substituents of the benzene ring.

Correlation of $\log k_{\text {obs }}$ with Hammett $\sigma^{-}$values gave a reasonable fit $\left(R^{2}=0.987\right.$, slope 1.00$)$ but not with the use of $\sigma\left(R^{2}=0.931\right.$, slope 1.52). The sign and the magnitude of the Hammett $\rho$ constant for the present reaction is in accordance with the dependence of the rate on the equilibrium $K_{1}=[8] /[7]$. The nucleophilicity of the nitrile group of the benzonitriles would depend on the substituents present. Electron-donating substituents would increase and electron-attracting groups decrease the nucleophilicity. For reactions with benzonitriles substituted with electron-donating groups we would accordingly have smaller concentrations of the carbocation 7 than with those with electron-attracting substituents and corresponding lower reaction rates.

Table 3. Product composition from the reaction of 8-exohydroxy-exo-THDCD $(2,1.10 \mathrm{mmol})$ with benzonitriles $(2.33$ $\mathrm{mmol})$ in concentrated sulfuric acid $(5 \mathrm{ml})$.

\begin{tabular}{llllll}
\hline & $\begin{array}{l}\text { Reaction } \\
\text { time } / \mathrm{h}\end{array}$ & $T /{ }^{\circ} \mathrm{C}$ & $\mathbf{3}$ & $\mathbf{5}$ & $\mathbf{6}$ \\
\cline { 5 - 7 } $\mathrm{NCC}_{6} \mathrm{H}_{4} \mathrm{X}-4$ & 1 & 10 & 4 & 71 & 22 \\
$\mathrm{H}$ & 20 & 20 & 1 & 79 & 8 \\
$\mathrm{H}$ & 1 & 10 & 4 & 73 & 19 \\
$\mathrm{Cl}$ & 20 & 20 & 1 & 68 & 8 \\
$\mathrm{Cl}$ & 1 & 10 & 2 & 77 & 8 \\
$\mathrm{NO}_{2}$ & & & & & \\
\hline
\end{tabular}

We have not found any reports correlating either the basicity and nucleophilicity of the benzonitriles or their reactivity in the Ritter reaction with the Hammett $\sigma$ constants. The correlation with the Hammett $\sigma^{-}$and not Hammett $\sigma$ for the nitro group may be explained by the possibility of through-conjugation between the nitro group and the cyano group, further decreasing the nucleophilicity of the cyano group.

The results from the reaction of the alcohol 3 with the benzonitriles in sulfuric acid are thus in accordance with Scheme 1 . The product compositions from the isomerisation reactions with other DPD derivatives or other nitriles (Tables 1 and 3) indicate that this scheme also applies in these cases. The results further show that a series of $N$-substituted amides can be prepared: The amides can be derived from different acids, and the $N$-derivative can be either the $N$-2-endo-THDPD-yl (4), N-2-exoTHDPD-yl (5) or N-exo-8-exo-THDPD-yl (6) amides according to the choice of reaction conditions.

Reactions with carbon monoxide. Koch and Haaf reacted endo-DHDPD (1) with carbon monoxide (110 bar) in sulfuric acid and obtained a mixture of the two acids 2-carboxy-endo-THDPD (15) and 2-carboxy-exo-THDPD $(\mathbf{1 7}$, Scheme 2$) .{ }^{7}$ To see if it was possible to obtain more extensive reactions with stronger acids we reacted 8-exochloro-exo-THDPD (13) with carbon monoxide (30 bar) and $\mathrm{SbF}_{5}$ in sulfur dioxide.

This reaction, but without carbon monoxide, has been reported. ${ }^{15}$ It was then found that the carbocation 7 (and its enantiomer) was formed rapidly from 13 and that it was stable at $-78^{\circ} \mathrm{C}$. However, at $-30^{\circ} \mathrm{C} 7$ in $\mathrm{SO}_{2}$ isomerised to the 1-adamantyl cation (Scheme 2). The structure of both cations was determined from quenching experiments and from NMR spectra.

In our experiments with carbon monoxide present, the result was analogous to that above if the reaction was quenched with ice after $30 \mathrm{~min}$ at $-78^{\circ} \mathrm{C}$. The only product was 2-carboxy-endo-THDPD $(\mathbf{1 5}, 60 \%)$. However, at increased reaction temperatures, the results were different from these reported: ${ }^{15}$ the 1 -adamantyl cation was not formed, instead quenching of the reaction gave a mixture of the two carboxylic acids $\mathbf{1 5}$ and $\mathbf{1 7}$ indicating that the two cations 7 and 11 were present in the reaction mixture. By increasing the reaction temperature, an increase in the yield of 17 was obtained and after $1 \mathrm{~h}$ at $20^{\circ} \mathrm{C}$ the product consisted of $2 \%$ of $15,92 \%$ of $\mathbf{1 7}$ and $6 \%$ of an unidentified carboxylic acid, presumably 8-exo-carboxyexo-THDPD (19, by analogy with the results from the reactions with nitriles). At prolonged reaction times at $20^{\circ} \mathrm{C}$ no further isomerisation took place, only tar formation.

The results from these reactions show the importance of the reaction conditions applied. In sulfur dioxide with $\mathrm{SbF}_{5}$ at $-78^{\circ} \mathrm{C}$, the cation $7 \mathrm{did}$ not isomerise, with or without carbon monoxide present (this work and Ref. 15). However, at higher temperatures, the reaction without carbon monoxide gave the 1-adamantyl cation; the 


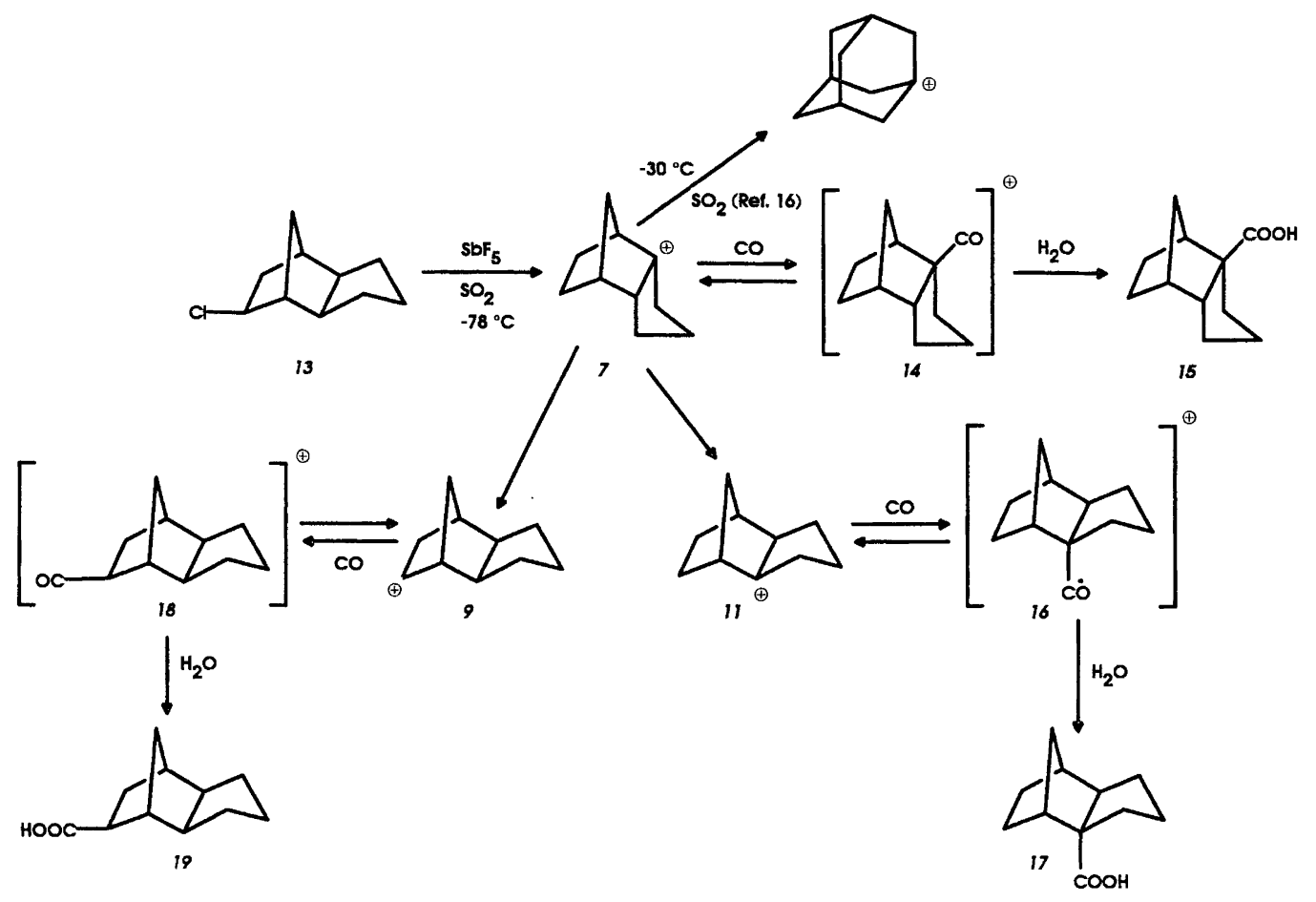

Scheme 2.

one with $\mathrm{CO}$ resulted mainly in the product from the equilibrium 11:16. Furthermore, with $\mathrm{BF}_{3}$ and acetonitrile in sulfur dioxide, the 8-exo-THDPD cation (9) in equilibrium with the nitrile adduct 10 a was stable at $-20^{\circ} \mathrm{C}$ (Table 1). Finally, in sulfuric acid with nitriles, the 8-exoTHDPD cation (9, from 8-exo-hydroxy-exo-THDPD) isomerised slowly to the 2-exo-THDPD cation (11, Table 3). In sulfur dioxide with $\mathrm{SbF}_{5}$ this cation isomerised rapidly to the cation $7 .{ }^{15}$

The reaction of $\mathbf{1 3}$ in sulfur dioxide with $\mathrm{SbF}_{5}$ and carbon monoxide did not result in 1-adamantanecarboxylic acid. The 2-exo-THDPD cation (11) is known to be in a local energy minimum. ${ }^{4.5}$ The equilibrium with the carbon monoxide adduct apparently increased this stability to an extent where no further isomerisation took place.

\section{Experimental}

The spectroscopic and chromatographic equipment used has been reported. ${ }^{3}$ Procedures for the preparations of the starting materials have also been reported: endo- $\mathrm{DH}$ DPD (1) by partial hydrogenation of DPD, ${ }^{10} 8$-exo-hydroxy-exo-THDPD (2) from acid-catalysed hydration of DPD followed by hydrogenation, ${ }^{9}$ 2-hydroxy-endoTHDPD (3) by $\mathrm{RuO}_{4}$ oxidation of endo-THDPD ${ }^{1}$ and 8-exo-chloro-exo-THDPD (13) from addition of $\mathrm{HCl}$ to DPD followed by hydrogenation. ${ }^{9}$ The sulfuric acid used in the reactions was $95-97 \%$.

The products of the reactions were identified by comparison of physical data with those of authentic samples.
In the case of new compounds such as the amides $\mathbf{5 a - e}$, the structures were determined by IR, ${ }^{1} \mathrm{H}$ NMR and ${ }^{13} \mathrm{C}$ NMR spectroscopy and ${ }^{13} \mathrm{C}-{ }^{13} \mathrm{C},{ }^{1} \mathrm{H}-{ }^{13} \mathrm{C}$ and ${ }^{1} \mathrm{H}-{ }^{1} \mathrm{H}$ correlation NMR spectroscopy. The details will be reported elsewhere.

Reactions of THDPD derivatives with acetonitrile. Each of the compounds $\mathbf{1}, \mathbf{2}$ and $\mathbf{3}(1.1 \mathrm{mmol})$ was dissolved in $\mathrm{CH}_{2} \mathrm{Cl}_{2}(1 \mathrm{ml})$ and added to a solution of acetonitrile $(0.5 \mathrm{ml}, 9.6 \mathrm{mmol})$ in $\mathrm{H}_{2} \mathrm{SO}_{4}(5 \mathrm{ml})$ at $0^{\circ} \mathrm{C}$. The mixture was stirred and heated rapidly to the reaction temperature $\left(10\right.$ or $\left.20^{\circ} \mathrm{C}\right)$. The reaction was stopped by mixing with ice water $(50 \mathrm{ml})$ and the product isolated by extraction with $\mathrm{CH}_{2} \mathrm{Cl}_{2}(3 \times 15 \mathrm{ml})$. The organic phase was washed with $\mathrm{NaHCO}_{3}$ solution and dried $\left(\mathrm{NaSO}_{4}\right)$. The mixture was analysed by $\mathrm{GC}$ and the results are given in Table 1. In the run with $\mathrm{CF}_{3} \mathrm{SO}_{3} \mathrm{H}-\mathrm{SO}_{2}, 1(149 \mathrm{mg}$, $1.11 \mathrm{mmol})$ was added to a solution of $\mathrm{CF}_{3} \mathrm{SO}_{3} \mathrm{H}(1 \mathrm{ml}$, $11.3 \mathrm{mmol})$ and $\mathrm{CH}_{3} \mathrm{CN}(78 \mathrm{mg}, 1.9 \mathrm{mmol})$ in $\mathrm{SO}_{2}(3 \mathrm{ml})$ under $\mathrm{N}_{2}$ at $-78^{\circ} \mathrm{C}$. The mixture was transferred to a glass-lined autoclave and kept at $20^{\circ} \mathrm{C}$ for $24 \mathrm{~h}$. The autoclave was cooled to $-78^{\circ} \mathrm{C}$ and the reaction mixture was poured over ice and worked up as above. In the run with $\mathrm{BF}_{3}, 2(80 \mathrm{mg}, 0.53 \mathrm{mmol})$ was added to a solution of $\mathrm{BF}_{3}(110 \mathrm{ml}$ gas, $4.5 \mathrm{mmol})$ and $\mathrm{CH}_{3} \mathrm{CN}(78 \mathrm{mg}$, $1.9 \mathrm{mmol})$ in $\mathrm{SO}_{2}(5 \mathrm{ml})$ at $-78^{\circ} \mathrm{C}$. The reaction mixture was kept at $-20^{\circ} \mathrm{C}$ for $24 \mathrm{~h}$ and worked up as for the run with $\mathrm{CF}_{3} \mathrm{SO}_{3} \mathrm{H}$. The reaction mixtures were analysed by GC (DB 1 capillary column, pentamethylbenzene as an internal standard). The acetamides were isolated by preparative HPLC on a Zorbax Sil column $(25 \times$ $2.12 \mathrm{~cm}$ ), injection volume $2 \mathrm{ml}$. The amide $\mathbf{6 a}$ was first 
eluted by the use of ethyl ether-acetonitrile $4: 1$ and then $4 \mathbf{a}$ followed by $5 \mathbf{a}$ by the use of hexane-ethyl acetate $4: 1$.

Formation of $\mathrm{N}$-(exo-8-exo-THDPD-yl)acetamide (6a) from $D P D$. DPD (211 mg, $1.60 \mathrm{mmol}$ ) was added to a solution of sulfuric acid $(0.5 \mathrm{ml})$ in acetonitrile $(5 \mathrm{ml})$ at $0^{\circ} \mathrm{C}$. The reaction mixture was kept at $20^{\circ} \mathrm{C}$ for $30 \mathrm{~min}$, poured into ice-water and worked up as above. The mixture (165 mg) of $N$-(8-exo-DHDPD-yl)- and $N$-(9-exoDHDPD-yl)-acetamide was dissolved in ethyl acetate $(50 \mathrm{ml})$ and hydrogenated over $\mathrm{PtO}_{2}(4.5 \mathrm{mg})$ at $4.5 \mathrm{bar}$ for $30 \mathrm{~min}$. After filtration and evaporation 6a was obtained ( $161 \mathrm{mg}, 52 \%$ from DPD). This product was identical with that obtained from the reaction of 2 with acetonitrile in $\mathrm{BF}_{3}-\mathrm{SO}_{2}$ (see above). IR $\left(\mathrm{KBr}, \mathrm{cm}^{-1}\right)$ : 3281 , 3066, 2971, 2946, 2865, 1638, 1548, 1437, 1446, 1374, 1354, 718. MS [ $m / z(\%$ rel. int. $)]: 193(51), 178(13), 150$ (21), 135 (13), 134 (100), 124 (19), 119 (13), 107 (11), 106 (17), 105 (10), 93 (11), 91 (16), 86 (17), 83 (13), 82 (41), 80 (12), $79(25), 73(21), 69(13), 67$ (23), 66 (28), 60 (59), 56 (20). ${ }^{13} \mathrm{C}$ NMR $\left\{{ }^{1} \mathrm{H}\right\}\left(100 \mathrm{MHz}, \mathrm{CDCl}_{3}\right): 169.34$, $52.09,46.95,46.81,45.00,39.86,39.47,32.07,31.66$, 29.60, 27.44, 23.34. ${ }^{1} \mathrm{H}$ NMR (400 $\left.\mathrm{MHz}, \mathrm{CDCl}_{3}\right): 5.3$ (1 H, NH), $3.65(1 \mathrm{H}, \mathrm{t} \mathrm{d}, 7.5,3.6 \mathrm{~Hz}), 2.05-1.78(9 \mathrm{H}$, $\mathrm{m}), 1.72(1 \mathrm{H}, \mathrm{m}), 1.64(1 \mathrm{H}, \mathrm{m}), 1.36$ (d quint., $J=11.2$, $2 \mathrm{~Hz}), 1.20(1 \mathrm{H}, \mathrm{m}), 1.14(1 \mathrm{H}, \mathrm{d} \mathrm{t}, J=12.8,4.0 \mathrm{~Hz})$, $1.06(1 \mathrm{H}, \mathrm{d}$ quint., $J=11.2,2 \mathrm{~Hz}), 0.95-0.83(2 \mathrm{H}, \mathrm{m})$.

Reactions of 2-hydroxy-endo-THDPD (3) with benzonitriles. These were performed in the same way for all four benzonitriles: 2-hydroxy-endo-THDPD (3, $76.8 \mathrm{mg}$, $0.505 \mathrm{mmol})$ in $\mathrm{CH}_{2} \mathrm{Cl}_{2}(0.5 \mathrm{ml})$ was added to a solution of the benzonitrile $(4.97 \mathrm{mmol})$ in $\mathrm{H}_{2} \mathrm{SO}_{4}(5.00 \mathrm{ml})$ at $0^{\circ} \mathrm{C}$ with vigorous stirring. After $1 \mathrm{~min}, 0.7 \mathrm{ml}$ of the solution was transferred to an NMR tube at $-20^{\circ} \mathrm{C}$. The first ${ }^{1} \mathrm{H}$ NMR spectrum was recorded after 8 min at $29.9^{\circ} \mathrm{C} . \mathrm{A} \mathrm{C}_{6} \mathrm{D}_{6}$ capillary was used for locking.

Reactions of 8-exo-hydroxy-exo-THDPD (2) with benzonitriles. $2(167 \mathrm{mg}, 1.10 \mathrm{mmol})$ in $\mathrm{CH}_{2} \mathrm{Cl}_{2}(1 \mathrm{ml})$ was added to a solution of benzonitrile $(2.33 \mathrm{mmol})$ in $\mathrm{H}_{2} \mathrm{SO}_{4}(5 \mathrm{ml})$ at $0^{\circ} \mathrm{C}$. The reaction mixture was worked up as for the reactions with acetonitrile and the results are given in Table 3.

Reactions of 8-exo-chloro-exo-THDPD (13) with carbon monoxide. These reactions were performed in a glasslined autoclave. 8-exo-Chloro-exo-THDPD $(13,283 \mathrm{mg}$, $1.66 \mathrm{mmol})$ was added to a solution of $\operatorname{SbF}_{5}(1 \mathrm{ml}$, $14.3 \mathrm{mmol})$ in sulfur dioxide $(3 \mathrm{ml})$ at $-78^{\circ} \mathrm{C}$. After $1 \mathrm{~h}$ under nitrogen ( 1 bar) carbon monoxide pressure (30 bar) was applied. After $30 \mathrm{~min}$ at $-78^{\circ} \mathrm{C}$, the pressure was released and the reaction mixture poured over ice $(50 \mathrm{~g})$. The water phase was extracted with $\mathrm{CH}_{2} \mathrm{Cl}_{2}(3 \times 15 \mathrm{ml})$.
The organic phase extracted with saturated sodium bicarbonate solution $(3 \times 15 \mathrm{ml})$, which was then made acidic and extracted with $\mathrm{CH}_{2} \mathrm{Cl}_{2}(3 \times 15 \mathrm{ml})$. After drying $\left(\mathrm{Na}_{2} \mathrm{SO}_{4}\right)$ and evaporation, 2-carboxy-endo-THDPD (15) was obtained $(179 \mathrm{mg}, 60 \%)$. GC analysis after methylation (diazomethane) showed it to be $98 \%$ pure with $2 \%$ of 2-carboxy-exo-THDPD (17). With the same procedure but with release of the $\mathrm{CO}$ pressure after $15 \mathrm{~min}$ at $-78^{\circ} \mathrm{C}$, blanketing with $\mathrm{N}_{2}$, and keeping the reaction temperature at $20^{\circ} \mathrm{C}$ for $1 \mathrm{~h}, 2$-carboxy-exo-THDPD was obtained $(17,180 \mathrm{mg}, 60 \%)$. GC analysis of the acid after methylation (diazomethane) showed it to be $92 \%$ pure with $2 \%$ of 2-carboxy-endo-THDPD (15) and $6 \%$ of an unidentified product.

Acknowledgments. Financial support from Norsk Hydro $\mathrm{A} / \mathrm{S}$ and Norges Teknisk Vitenskapelig Forskningsråd is gratefully acknowledged.

\section{References}

1. Bakke, J. M. and Lundquist, M. Acta Chem. Scand, Ser. B 40 (1986) 430.

2. Bakke, J. M. and Lundquist, M. Acta Chem. Scand. 44 (1990) 860.

3. Bakke, J. M. and Brænden, J. E. Acta Chem. Scand. 45 (1991) 418

4. Fort, R. C. Jr. Adamantane, the Chemistry of Diamond Molecules, Marcel Dekker, New York 1976.

5. Olah, G. A. Ed. Cage Hydrocarbons, Wiley, New York 1990.

6. Olah, G. A., Surya Prakash, G. K. and Sommer, J. Superacids, Wiley, New York 1985.

7. Koch, H. and Haaf, W. Ann. Chem. 638 (1960) 111.

8. Nelson, G. L. and Cuo, C.-L. Synthesis (1975) 105.

9. Bruson, H. A. and Riener, T. W. J. Am. Chem. Soc. 67 (1945) $723,1178$.

10. Lundquist, M. Disyclopentadien som råstoff for finkjemikalier, Norwegian Institute of Technology, University of Trondheim, 1986.

11. Buntin, G. A. US Patent 3173950 (1962).

12. Ritter, J. J. and Minieri, P. P. J. Am. Chem. Soc. 70 (1948) 4045; Krimen L. I. and Cota, D. J. Org. React. 17 (1969) 213.

13. Bakke, J. M., Brænden, J. E. and Krane, J. Magn. Reson. Chem. 30 (1992) 298

14. Sorensen, T. S. and Whitworth, S. M., p. 65 in Ref. 5.

15. Olah, G. A., Surya Prakash, G. K., Shib, G. J., Krishnamurthy, V. V., Mateescu, G. D., Liang, G., Sipos, G., Buss, V., Gund, T. V. and Schleyer, P. v. R. J. Am. Chem. Soc. 107 (1985) 2764

16. Arnett, E. M. In: Cohen, S. G., Streitweiser, A. and Taft, R. W., Eds., Progress in Physical Organic Chemistry, Vol. 1, Interscience, New York 1963.

17. Deno, N. C. and Wisotsky, M. J. J. Am. Chem. Soc. 85 (1963) 1735.

18. Deno, N. C., Gaugler, R. W. and Wisotsky, M. J. J. Org. Chem. 31 (1966) 1967.

Received June 29, 1993. 